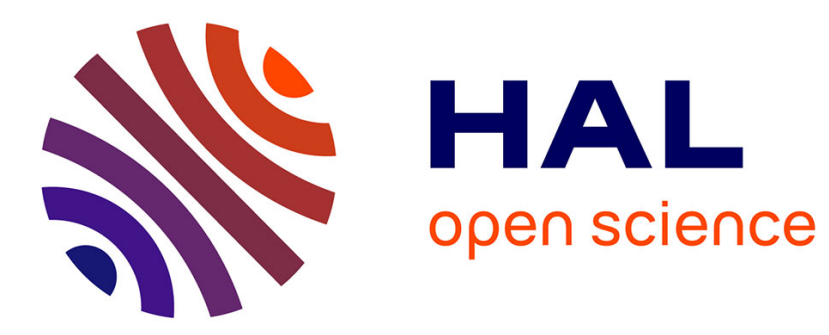

\title{
Flavor additives facilitate oral self-administration of nicotine solution in mice
}

Salma Tannous, Florence Darlot, Martine Cador, Stephanie Caille

\section{To cite this version:}

Salma Tannous, Florence Darlot, Martine Cador, Stephanie Caille. Flavor additives facilitate oral self-administration of nicotine solution in mice. Psychopharmacology, 2021, 238 (8), pp.2235-2247. 10.1007/s00213-021-05848-1 . hal-03436915

\section{HAL Id: hal-03436915 https://hal.science/hal-03436915}

Submitted on 19 Nov 2021

HAL is a multi-disciplinary open access archive for the deposit and dissemination of scientific research documents, whether they are published or not. The documents may come from teaching and research institutions in France or abroad, or from public or private research centers.
L'archive ouverte pluridisciplinaire HAL, est destinée au dépôt et à la diffusion de documents scientifiques de niveau recherche, publiés ou non, émanant des établissements d'enseignement et de recherche français ou étrangers, des laboratoires publics ou privés. 


\section{Psychopharmacology \\ Flavor additives facilitate oral self-administration of nicotine solution in mice --Manuscript Draft--}

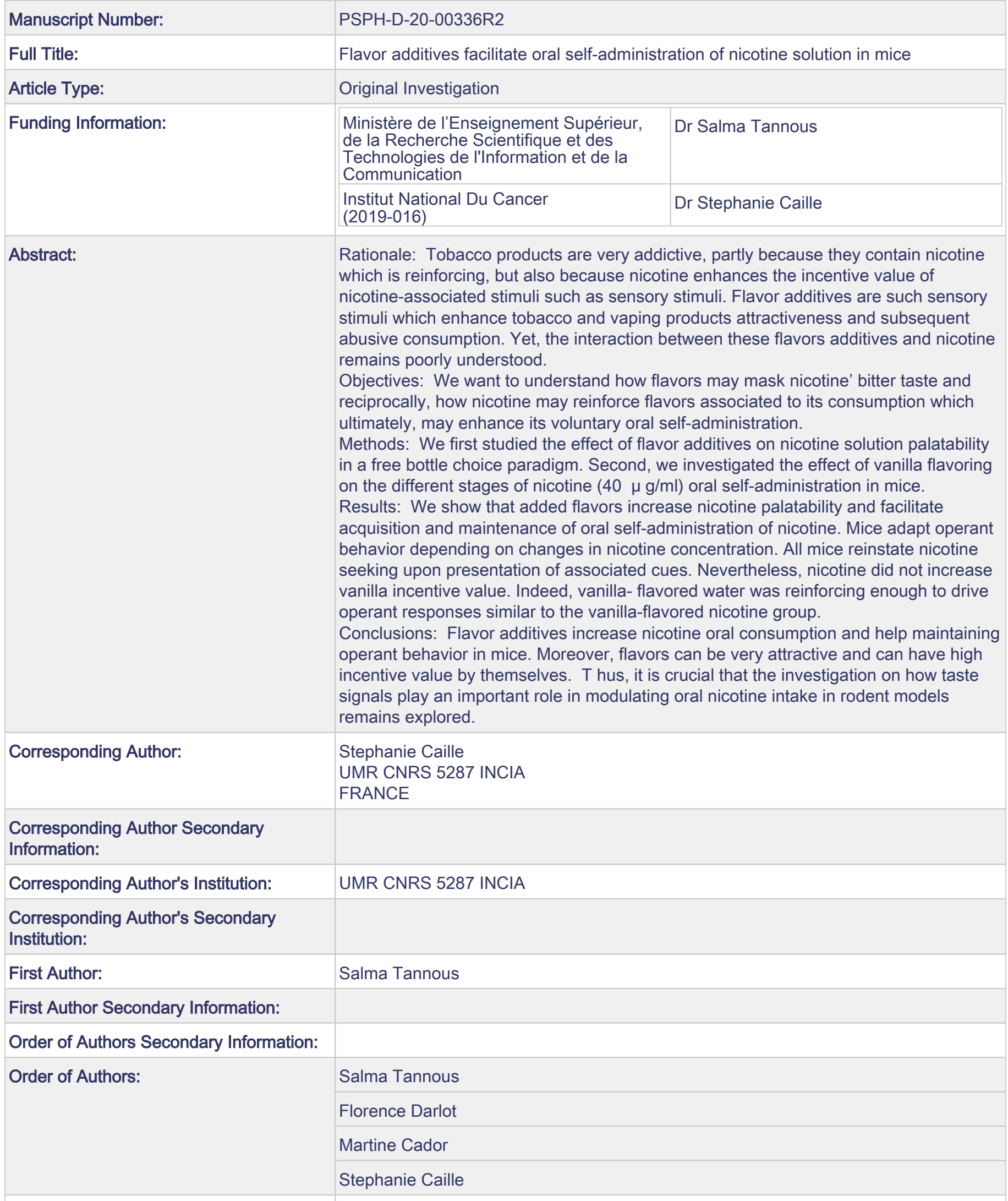

Author Comments: 
Reviewer \#1: The authors have addressed all of my initial concerns adequately with the inclusion of the appropriate nicotine only group for the self-administration experiments and using the suggested statistical analysis approach. Additionally, the indication of no presence of cotinine in the control groups is sufficient.

Thank you for all the suggestions, it greatly improved our manuscript.

Reviewer \#3: The results of the present study are interesting even though there are several important limitations (adolescence exposure, oral administration of nicotine solutions, inbred mice, extinction procedure). Other reviewers have already pointed out a lot of relevant comments and I have only some points that need to be discussed.

In the abstract: what is 'abusive consumption' (especially regarding nicotine) ?

We have corrected the sentence such as "Flavor additives are such sensory stimuli which enhance attractiveness, as well as use and abuse of tobacco and vaping products"

The title should indicate nicotine solution: Flavor additives facilitate oral self-administration of nicotine SOLUTION in mice

We have made the requested change

'Mice were first trained to nose-poke for a liquid reward of saccharin $0.1 \%$ sweet solutions': can the authors be sure that saccharin pre-exposure did not influenced the results on future selfadministration.

We think that prior training with saccharin facilitates acquisition (all mice show similar performances) but does not interfere with the specificity of the results of future self-administration since "test solutions". Indeed, the expression of differences between groups starts with selfadministration of vanilla vs. vanilla +nicotine vs. nicotine-alone.

On figure 1, the age of the animals should be indicated

We have inserted the age of the animals for each experiment in the legend of figure 1

On figure $2 \mathrm{a}$, results on nicotine preference should be given.

This figure shows 1-bottle consumption tests; thus, it presents data for basal water vs. basal nicotine. It is not a 2-bottle choice procedure, it cannot be expressed in preference for a solution.

The 'extinction-reinstatement' term should be changed to be less confusing because more classical procedure is expected from this term. It is more a measure of responding during a short single cuedrug omission session. Thus, it is more a single extinction responding session and not sure that a true 'reinstatement' is assessed here.

To avoid the confusion with the more classical protocol of reinstatement, we have included the exact definition of the between-within session reinstatement procedure as defined in Shalev et al, 2002. We have included the reference in the paper for further information if needed.

Is there a link (association) between intake in the two-bottle choice situation and the operant selfadministration situation? (Correlation in the same individuals)

Unfortunately, we cannot answer this question because we did not assess these different behavioral components in the same animals. However, it will be very interesting to run this correlation test in the next set of experiments.

Can the present results be influenced by the inbred mice use here ? In other words do C57BL/6J more prone/resistant to nicotine intake? (see for example : Chem Senses. 2009;34(1):27-35. doi: $10.1093 /$ chemse/bjn049. Variation in nicotine consumption in inbred mice is not linked to orosensory ability. Rebecca Glatt et al PMID: 18775876 ).

We thank the reviewer for this bibliographic reference. Considering the paper mentioned here, it seems that C57BL6/J may be prone to higher intake of nicotine solution in a 2-bottle choice test on consecutive $48 \mathrm{~h}$ period when compared to other strains. But this strain is similar to the others in brief access conditions.

In our experimental conditions, it was important that mice were prone to drink to avoid a floor effect, but it was important as well not to have a ceiling effect. Actually, we show that the strain C57/BL6J does not prevent from having a potentiation of nicotine intake by the addition of vanilla flavor in both drinking test designs (bottle and self-administration). 


\title{
Flavor additives facilitate oral self-administration of nicotine SOLUTION in mice
}

\author{
Salma Tannous, Florence Darlot, Martine Cador, Stephanie Caille*
}

Univ. Bordeaux, CNRS, EPHE, INCIA, UMR5287 F-33000 Bordeaux

*Corresponding author :

Stephanie Caille, CNRS-UMR5287, Université de Bordeaux BP31, 146 rue Léo Saignat, 33076 Bordeaux, France. E-mail address: stephanie.caille-garnier@u-bordeaux.fr

\section{Acknowledgments:}

This study was supported by the Centre National de la Recherche Scientifique, the University of Bordeaux and Region Aquitaine and Institut National du Cancer (INCa 2019-016 to SC). ST was supported by the "Ministère de la Recherche et de l'Enseignement Supérieur". The authors thank Yoan Salafranque for the care provided to the mice during the experiments. The authors declare no conflict of interest. 


\section{ABSTRACT}

Rationale: Tobacco products are very addictive, partly because they contain nicotine which is reinforcing, but also because they include appealing aromas and tastes. Flavor additives are such sensory stimuli which enhance attractiveness, as well as use and abuse of tobacco and vaping products. Yet, the interaction between these flavors additives and nicotine remains poorly understood.

Objectives: We want to understand how flavors may reduce nicotine' aversive taste and how it may enhance its voluntary oral self-administration in mice.

Methods: We first studied the effect of flavor additives on nicotine solution palatability in a free bottle choice paradigm. Second, we investigated the effect of vanilla flavoring on the different stages of nicotine $(40 \mu \mathrm{g} / \mathrm{ml})$ oral self-administration in mice.

Results: We show that adding flavors increase nicotine palatability and facilitate acquisition and maintenance of oral self-administration when compared to nicotine-alone group. Mice adapt their operant behavior depending on changes in nicotine concentration. All mice reinstate nicotine seeking upon presentation of associated cues. Nevertheless, vanilla-flavored nicotine was not more reinforcing than vanilla-flavored water which was reinforcing enough to drive similar operant response rates.

Conclusions: Flavor additives increase nicotine oral consumption and help maintaining operant behavior in mice. Moreover, flavors can be very attractive and can have high reinforcing value by themselves. Thus, it is crucial that the investigation on how taste signals play an important role in modulating oral nicotine intake in rodent models remains explored.

Keywords: addiction, reward, nicotine, flavor, oral self-administration, free bottle choice, mice 


\section{INTRODUCTION}

Tobacco products have a powerful taste and sensory effects on the buccal cavity and airways. In humans, preferences develop to specific flavors and packaging, raising debates about sensory experiences in smoking habits (Ayo-Yusuf and Agaku 2015). Nicotine, the primary psychoactive molecule in tobacco products, has highly addictive potential (Cohen et al. 2012; Grieder et al. 2014; Vandaele et al. 2018) despite weak reinforcing effects compared to cocaine for instance (Clemens et al. 2010). Moreover, when presented orally, the nicotine bitter taste causes avoidance (Smith and Roberts 1995) and smoking is usually aversive to naïve smokers (Lee et al. 1993). Yet, nicotine continues to be abused in conventional cigarettes as well as in the new electronic nicotine delivery devices (ENDS) because of all the additives to improve taste acceptance.

Noticeably, nicotine is always associated with numerous additives, especially in ENDS such as ecigarettes (e-cig) where the e-liquids can contain more than 7000 additives (Zhu et al. 2014) including sugars, flavors such as strawberry, licorice, menthol, vanilla, chocolate, etc. These chemicals are usually used in order to mask nicotine's bitterness and to confer to each e-liquid its characteristics by modulating harshness and astringency (Harris et al. 2019). One expects that enhancing a product appeal by the use of additives encourages repeated nicotine exposures, facilitating acceptability and transition to abusive consumption and addiction (Vogel et al. 2019). Thus, e-cig and ENDS, which at first were presented as putative replacement therapy to cigarette smoking, may become more recreational or addictive.

We know from previous work that sweet or aromatic additives associated with nicotine facilitate acquisition and maintenance of nicotine intravenous self-administration (Palmatier et al. 2020; Wickham et al. 2018). Specifically, menthol facilitates acquisition of nicotine intravenous selfadministration, maintains vulnerability to nicotine seeking behavior (Biswas et al. 2016; Nesil et al. 2019) and increases nicotine-induced dopamine transmission in the nucleus accumbens (Wickham et al. 2018; Zhang et al. 2018). Reciprocally, incentive properties of drug-taking associated cues are 
enhanced by nicotine (Grimm et al. 2012; Palmatier et al. 2013). It was first shown that the presence of visual stimuli associated with nicotine intravenous self-administration increases nicotine volitional intake due to nicotine's secondary reinforcing properties (Chaudhri et al. 2006; Chaudhri et al. 2006). Recently, Palmatier and colleagues demonstrated that incentive properties of olfactogustatory cues could be reinforced by nicotine as well (Palmatier et al. 2013). Altogether, these findings suggest that sensory cues, and more specifically oral cues are crucial in the acquisition of nicotine-related behaviors when nicotine is given peripherally, whether given contingently or not. However, preclinical studies investigating how olfactogustatory stimuli such as flavor additives may also control nicotine oral self-administration remain poorly developed (Collins et al. 2012).

Based on previous findings, our hypothesis was that oral signals and nicotine bidirectional interactions are crucial for the rewarding effect of oral flavored unsweetened nicotine. On one hand, flavored oral cues may improve the palatability of nicotine and on the other hand, nicotine secondary reinforcing effects enhance the values of the associated flavors. Thus, we expected that the combination of nicotine with multisensory cues enhanced nicotine reinforcing properties, and subsequently, increased oral self-administration of the drug. To test this hypothesis, we first studied the palatability of nicotine flavored solution by examining free-access consumption using a two bottle-choice paradigm (experiment 1). Second, we characterized vanilla flavored nicotine oral selfadministration in mice (experiment 2). Vanilla flavor is one of the most used flavors in tobacco products and increases tobacco attractiveness (Krusemann et al. 2019). Even if its use was banned in combustible cigarettes market in 2016, yet there is no regulation regarding its addition to the new tobacco products such as ENDS. Thus, the present study deals with the crucial issue of the role of the concomitant oral administration of nicotine and oral sensory signals in the vulnerability to nicotine addictive properties. 


\section{MATERIAL AND METHODS}

\section{SUBJECTS}

For each experiment, we used male C57BL6J mice issued from Charles River laboratories (France) and local breeding in our laboratory. Animals were maintained in a thermoregulated animal housing $\left(22^{\circ} \mathrm{C}\right)$ and in inverted cycle (night from 8:00am to 8:00pm), allowing the experiments to take place during the animal active phase. Mice were group-housed and had access to food and water ad libitum when no other regimen is noted. All experiments were in accordance with French (council directive 2013-118, February 1, 2013) and International (directive 2010-63, September 22, 2010, European Community) legislations for the care and use of laboratory animals and validated by the French Ethics Committee (Approval APAFIS\#3265-20 15121811059640 v6).

\section{DRUGS}

Nicotine hydrogen tartrate (Sigma-Aldrich ${ }^{\circledR}$, France) was dissolved in flavored or non-flavored tap water at concentrations ranging from 40 to $120 \mu \mathrm{g} / \mathrm{ml}$ and $\mathrm{pH}$ adjusted to 7.7-7.9 for optimal oral nicotine absorption. Saccharin 0.1\% (Sigma-Aldrich ${ }^{\circledR}$, France) was dissolved in tap water. Coconut (Arômes Caraibes ${ }^{\circledR}$ ) and vanilla (Lechampion bio ${ }^{\circledR}$ ) flavors were purchased from local stores and diluted at different concentrations $(0.01,0.1$ and $1 \%)$ in tap water.

EXPERIMENT 1 Free-access consumption of flavored nicotine solution: one bottle self-administration and two-bottle choice test

The aim here was to determine whether nicotine aversive taste properties could be modified by adding flavored additives (fig 1a). To do so, we used 14 male C57BL6J adolescent mice at the average age of 35 days (PND35) and weighing 13.65g in average at the start of the experiment. They were single-housed into plastic cages to allow individual measures of liquid consumption.

At first, basal water consumption was measured with water over $72 \mathrm{~h}$ (D1 to D3) and we reported the average amount of experimental solution consumed over a $24 \mathrm{~h}$-period $(n=14)$. Then, nicotine $(60 \mu \mathrm{g} / \mathrm{ml})$ consumption was measured over $24 \mathrm{~h}$ (D9). Animals were next assigned to 2 experimental groups: nicotine+coconut $(\mathrm{n}=7)$ and nicotine + vanilla $(\mathrm{n}=7)$.

Second, flavored (flavors at $0.01,0.1$ and $1 \%)$ nicotine $(60 \mu \mathrm{g} / \mathrm{ml})$ was compared to tap water (D18D20) or to flavored water (D21-D22) in a two-bottle free choice. Tests were all performed in the home cages. We reported the amount of experimental solution consumed over a $24 \mathrm{~h}$-period. Bottles were alternated from left to right after each measure in order to avoid effect of position preference. Data were given as a consumption relative to body weight $(\mathrm{ml} / \mathrm{g})$. 
Data were analyzed using STATISTICA ${ }^{\circledR}$ and GraphPad Prism ${ }^{\circledR}$. Paired-t tests were used to compare basal consumptions (water vs. nicotine). The effects of coconut vs. vanilla in nicotine solution were assessed using a two-way repeated measures ANOVA (flavor-by-dose) which compared the effect of different flavors at different concentrations on preference scores over water or flavored water. Comparisons of individual score preferences to a standard theoretical value of $50 \%$ were also used to evaluate the liquid solution aversiveness. Statistical significance for all analyses is fixed as $\mathrm{p} \leq 0.05$ and all data are represented as mean \pm SEM.

Figure 1 here

EXPERIMENT 2 Study of flavored nicotine oral self-administration (OSA) in operant chambers

The aim of this experiment was to investigate the reinforcing properties of nicotine when associated with oral cues (fig 1b). Here, we used 34 male adolescent mice aged PND 35-40 at the beginning of the experiment and weighing $19.2 \mathrm{~g}$ in average. Home cage water bottles were removed 2 hours before the start of the session to facilitate acquisition of OSA.

\section{Apparatus and general procedure}

Oral self-administration training was conducted in conditioning chambers $(15 \times 18 \times 22 \mathrm{~cm}$, Imetronic, France), each located inside a sound and light-attenuating wooden chamber. Each experimental chamber had an operant panel equipped with two nose-poke holes and a liquid dipper was inserted in between. External pumps were fitted with syringes connected with Tygon tubing to a fluid swivel. Illumination of a dim house-light for 3 seconds signaled the start of each test session lasting 30, 60 or 120 min depending on the test session. Visits in the "active" hole resulted in a $50 \mu 1$-liquid reward delivered into the dipper. Each reward delivery was accompanied by the presentation of a visual stimulus consisting of a $3 \mathrm{~s}$ cue light above the active nose-poke. After each delivery, mice had to empty the liquid dispenser to enable the next count of reinforced visits. Visits to the inactive hole were recorded but had no consequences. At the end of the training session, illumination of the house-light again signaled the termination of the session and the beginning of a $15 \mathrm{~min}$ "nodrug" period during which nose-pokes were without scheduled consequences (no drug delivery and no cue light).

\section{Saccharin pretraining}

Mice were first trained to nose-poke for a liquid reward of saccharin $0.1 \%$ sweet solutions (fixed ratio 1 and 2) on daily $30 \mathrm{~min}$-session for two weeks, in order to acquire efficient instrumental response prior nicotine OSA (fig 1b). The general training procedure was as mentioned above except 
that reward delivery was neither associated with a cue light nor a 15 min "no-drug" period at the end of the session.

\section{Acquisition, maintenance and dose-response curve}

Mice were then divided into 3 groups of equal performances: a first group receiving vanilla 1\% (Vanilla; $n=11$ ), a second group receiving nicotine flavored with vanilla $1 \%$ (Nicotine+Vanilla; $\mathrm{n}=12$ ) solution ranging from 40 to $120 \mu \mathrm{g} / \mathrm{ml}$ depending on the stage of the experiment, and a third group of mice receiving nicotine alone $(40 \mu \mathrm{g} / \mathrm{ml})$ for reward. Training for nicotine and flavored nicotine started at $40 \mu \mathrm{g} / \mathrm{ml}$ on a FR2 schedule and then switched to FR3 schedule of reinforcement (30-min sessions) (fig 1). All fixed ratio OSA sessions ended with the 15 min "nodrug" period to examine persistent drug seeking behavior while there were no drug and no cue light. In order to test the effect of a longer access to nicotine, animals were also tested for OSA on FR3 scheduled session lasting for $60 \mathrm{~min}$. Finally, in order to describe the reinforcing and aversive effects of flavored nicotine at higher concentrations, mice were also trained on FR3 60minsessions at doses of nicotine 80 and $120 \mu \mathrm{g} / \mathrm{ml}$ and tested for motivation and reinstatement (fig $1 \mathrm{~b}$ ).

\section{Motivation}

After OSA stabilization, motivation for flavored water or flavored nicotine was tested in a progressive ratio schedule of reinforcement (fig $1 \mathrm{~b}$ ). Within the same session, the number of visits in the active nose-poke hole to obtain the reward increased progressively by 2 (PR2). The session lasted 120 minutes and we applied a cut off after 15 minutes without a reward delivery. The breaking point, which is an index of motivation, was calculated on the last ratio a mouse completed before the session was stopped.

\section{Sensitivity to Drug and Drug-associated Cues}

A dose-response curve was performed with the presentation of increasing doses of nicotine in the following order: $0,20,40$ and $80 \mu \mathrm{g} / \mathrm{ml}$; in order to determine behavioral sensitivity to reinforcing effects of nicotine alone and flavored nicotine solutions (fig.1b). For each dose, the session was 30 min duration with a FR3 schedule of reinforcement.

To understand the role of each sensory stimulus in flavored nicotine OSA, mice performed a session similar to a standard OSA session, except that the reward would vary according to the test. In order to examine the response to nicotine omission, mice from the flavored nicotine group would receive a solution of vanilla only - such as the vanilla control group- with the presentation of the contingent cue-light for the whole session. We also tested the response to simultaneous nicotine and vanilla omission. This last test was performed with or without the presentation of the contingent cue-light. 


\section{Between-within session of Cue and drug-reinstatement procedure}

In this reinstatement procedure (Shalev et al. 2002), extinction training and tests for reinstatement of drug seeking are examined on the same day following the last day of drug self-administration (fig 1b). Each session began with a $30 \mathrm{~min}$ period of extinction during which mice had access to the active and inactive nose-poke holes but without any consequences. Then, the visual cue light above the active hole was illuminated for $10 \mathrm{sec}$ and a free liquid reward delivery occurred. Each subsequent nose-poke in the active hole resulted in a $3 \mathrm{sec}$ light stimulus presentation. Reinstatement was measured by the difference in active responding between the 30 min extinction period and the post-stimulus presentation period. Finally, at the end of the reinstatement test, animals were left for $15 \mathrm{~min}$ in the chamber while the absence of drug was signaled by the house light on. This was an index of persistent seeking while the drug is unavailable.

\section{Cotinine ELISA}

Given that cotinine is the main nicotine metabolite, we examined serum cotinine levels to evaluate nicotine impregnation following its oral ingestion (fig 1a). Mice of the flavored nicotine group ( $\mathrm{n}=11)$ were divided into two groups: mice after training with nicotine $40 \mu \mathrm{g} / \mathrm{ml}(\mathrm{n}=6)$ and with nicotine $120 \mu \mathrm{g} / \mathrm{ml}(\mathrm{n}=5)$. Mice trained for vanilla flavored water were sampled for control $(\mathrm{n}=11)$. At $90 \mathrm{~min}$ post-OSA session, mice were anesthetized with a mixture of pentobarbital $(300 \mathrm{mg} / \mathrm{kg})$ and lidocaine $(30 \mathrm{mg} / \mathrm{kg})$ to allow intra-cardiac blood sampling. Approximately $0.5 \mathrm{ml}$ of blood was collected in tubes and immersed for 4 hours into a $37^{\circ} \mathrm{C}$ water bath to allow coagulation and serum collection after centrifugation at $4000 \mathrm{rpm}$ for $10 \mathrm{~min}$ at $4{ }^{\circ} \mathrm{C}$. Samples were stored at $-20^{\circ} \mathrm{C}$ until dosage. Cotinine serum dosage was performed using commercially available Cotinine direct ELISA kit (Calbiotech Inc, USA). Two $10 \mu 1$ aliquots of serum from each animal were used as replicates in the ELISA assay. Absorbance was measured on ELISA reader (POLARstar Omega, BMG LabtechPlateforme de Biochimie et de Biophysique, Bordeaux Neurocampus) at $450 \mathrm{~nm}$ within $15 \mathrm{~min}$ following the addition of the stopping reagent. Cotinine standard curve $(0-100 \mathrm{ng} / \mathrm{ml})$ was constructed in order to calculate cotinine concentrations from absorbance.

\section{Statistical analysis}

Data were analyzed using STATISTICA ${ }^{\circledR}$ and GraphPad Prism ${ }^{\circledR}$. Repeated measures ANOVA were performed to compare vanilla, nicotine+vanilla and nicotine groups across oral selfadministration sessions. When an interaction was significant, the comparison was followed by corresponding one-way ANOVA and Tukey or Sidak post-hoc analyses. Serum cotinine dosage data were analyzed by using parametric t-test comparisons followed by a Welch's correction. Statistical significance for all analyses was fixed as $p \leq 0.05$. 


\section{RESULTS}

EXPERIMENT 1 Oral consumption of flavored nicotine: one bottle self-administration and two-bottle choice test

Figure 2 Here

All animals were first tested for water consumption to evaluate basal liquid intake, followed by nicotine consumption test in order to evaluate the aversive properties of non-flavored nicotine (fig2a representing individual values). Liquid intake, $0.25 \pm 0.05 \mathrm{ml} / \mathrm{g}$ for water, decreased to $0.18 \pm 0.04 \mathrm{ml} / \mathrm{g}$ when nicotine $60 \mu \mathrm{g} / \mathrm{ml}$ was added to the solution (Paired t-test, $\mathrm{t}(13)=8.27, \mathrm{p}<0.001$ ).

Then, in a two-bottle choice test with a dose-response on the flavor concentration, we measured preference for flavored nicotine over water (Fig 2b). ANOVA with repeated measures show that vanilla flavored nicotine was significantly preferred to coconut flavored nicotine (flavor main effect, $\mathrm{F}(1,12)=4.60, \mathrm{p}=0.05)$. Score for coconut $1 \%$ flavored nicotine was significantly lower than $50 \%$ $[\mathrm{t}(6)=-3.65, \mathrm{p}=0.01]$, indicating an aversion, while vanilla flavored nicotine score was significantly higher than $50 \%$, reflecting a preference versus water $[\mathrm{t}(6)=3.5, \mathrm{p}<0.05]$. There was neither significant flavor concentration effect $[\mathrm{F}(2,24)=0.56, \mathrm{p}=0.58]$ nor concentration $\mathrm{x}$ flavor interaction $[\mathrm{F}(2,24)=2.62, \mathrm{p}=0.09]$.

Finally, we performed a dose-response on vanilla concentrations in a tow-bottle choice procedure and measured the preference for vanilla flavored nicotine over vanilla flavored water solution (fig 2c). Preference score for $0.1 \%$ was significantly lower than the score at $1 \%$ (paired t-test, $\mathrm{t}(6)=-2.68$, $\mathrm{p}=0.04$ ). When compared to preference score $50 \%$, nicotine in vanilla $0.1 \%$ was still aversive $(\mathrm{p}<0.01)$ while vanilla $1 \%$ made nicotine taste isopalatable to vanilla $1 \%$ only [test de Student, $\mathrm{t}(6)=0.04, \mathrm{p}>0.05 \mathrm{~ns})$.

EXPERIMENT 2 Study of flavored nicotine oral self-administration (OSA) in operant chambers

Acquisition and maintenance of vanilla flavored nicotine OSA

Figure 3 Here

At the end of saccharin pretraining, mice were divided into 3 groups with equal performances (See fig S1). On the last day of training, saccharin reward obtained were equivalent in vanilla (10.91 \pm 1.51 rewards), vanilla flavored nicotine (12.67 \pm 1.60 rewards), and nicotine $(11.45 \pm 1.69$ rewards $)$ groups (one-way ANOVA, F $(2,31)=0.22, \mathrm{p}>0.05)$. 
Then, we tested the addition of vanilla flavor to nicotine $(40 \mu \mathrm{g} / \mathrm{ml})$ on the maintenance of oral selfadministration (fig 3a). All groups acquired solid and comparable responding directed to the active hole across increasing schedules of reinforcement (FR2 to FR3) or exercise length (FR3 60 min). On FR2 schedule, the comparison of acquisition did not show significant group $\mathrm{x}$ time interaction $[F(12,186)=1.41, p>0.05]$, nor main group effect $[F(2,31)=0.58, p>0.05]$. However, there was a significant session effect $[F(6,186)=3.98, p=0.003]$. On FR3 30 min schedule, all groups adapted to the new ratio (group effect $[\mathrm{F}(2,31)=1.26, \mathrm{p}>0.05]$, significant session effect $[\mathrm{F}(6,186)=5.25$, $\mathrm{p}<0.001)$. The group $\mathrm{x}$ time interaction $[\mathrm{F}(12,186)=2.01, \mathrm{p}=0.02]$, followed by a Tukey post-hoc comparison indicated that nicotine group was significantly different from vanilla group on session \#5 ( $\mathrm{p}=0.03$ ). Finally, all groups similarly adapted to the increase of FR3 session length to 60 min, active responding (group effect $[\mathrm{F}(2,31)=1.65, \mathrm{p}>0.05]$, group $\mathrm{x}$ time interaction $[\mathrm{F}(6,186)=0.73$, $\mathrm{p}>0.05]$ ). Performances on the active nose poke did not differ during the 7 sessions [no session main effect, $F(6,186)=1.88, \mathrm{p}>0.05]$.

Repeated measure ANOVA of visit rates in the inactive nose-poke over the 3 schedules of reinforcement (see fig S2a) showed that there was a group effect $[\mathrm{F}(2,31)=4,07, \mathrm{p}=0.03]$, and Tukey post-hoc indicated that overall nicotine mice did more visits in the inactive nose-poke hole than vanilla $(p=0.03)$ or than nicotine+vanilla $(p=0.01)$. Increasing the length of the session to 60 increased the number of inactive nose-poke visits in the three groups $[\mathrm{F}(2,62)=4.08, \mathrm{p}=0.04]$, but schedule $x$ group interaction $[F(4,62)=0.62, p>0.05]$ was not significant.

Repeated measure ANOVA analysis on the number of rewards received (fig 3b, comparison on the average of the last 3 days of acquisition for each schedule of reinforcement) did not indicate group $\mathrm{x}$ session condition interaction $[\mathrm{F}(4,62)=1.10, \mathrm{p}>0.05]$. There was a significant effect of schedule changes $[\mathrm{F}(2,62)=17.61, \mathrm{p}<0.001]$, post hoc indicated that as expected, the number of rewards obtained was the highest for FR3 $60 \mathrm{~min}$ (Tukey $\mathrm{p}<0.001$ when compared to FR2 or FR3 $30 \mathrm{~min}$ ). There was also a significant group effect $[F(2,31)=22.91, p<0.001]$, nicotine mice showed the lowest number of rewards (Tukey $p<0.01$ when compared to vanilla or to vanilla+nicotine).

Oral self-administration of flavored nicotine solution is sensitive to change in nicotine concentration Figure 4 Here

Two-way repeated ANOVA of active responding for nicotine and flavored nicotine groups (fig 4a) showed a significant groupxdose interaction $[\mathrm{F}(3,63)=3.11, \mathrm{p}<0.05]$ and a significant dose effect $[F(3,63)=5.97, p<0.001]$. Post-hoc analysis indicated that for the dose 20, the nicotine group was significantly different from the nicotine+vanilla group (Sidak, $\mathrm{p}<0.05$ ). Inactive responding was 
significantly higher in nicotine than in the nicotine+vanilla group [group effect $F(1,21)=4.81$, $\mathrm{p}<0.05$, interaction $\mathrm{F}(3,63)=2.79, \mathrm{p}<0.05$; fig S2b] Two-way repeated ANOVA of on number of rewards obtained (fig $4 \mathrm{~b})$ indicated that there was a significant groupxdose interaction $[\mathrm{F}(3,63)$ $=7.79, \mathrm{p}<0.001]$, a significant dose effect $[\mathrm{F}(3,63)=11.15, \mathrm{p}<0.001]$ and a significant group effect $[F(2,21)=21.26, p<0.001]$. Overall, nicotine mice obtained less rewards than nicotine+vanilla mice (Sidak post-hoc $\mathrm{p}>0.01$ ) except at the dose 0 (post-hoc n.s.). This reduction in responding was transposed in a significant lower intake in nicotine group compared to nicotine+vanilla group [ANOVA group effect, $F(1,21)=24.44, p<0.001]$. Increasing nicotine dose resulted in enhanced total intake [groupxdose interaction, $\mathrm{F}(2,42)=13.15$, $\mathrm{p}<0.001$, dose effect $(2,42)=36.84, \mathrm{p}<0.001$; fig 4c] in both groups, but the nicotine alone lead to a plateau when reaching the dose 40 (Tukey post-hoc, 40 vs. 80 , n.s.).

\section{Effects of Nicotine, flavor omission with or without cue light omission on oral self-administration} Figure 5 Here

First, for nicotine omission test, nicotine+vanilla and vanilla groups had to work for vanilla flavored water while nicotine had to work for water only (fig 5a). A two-way ANOVA indicated significant group $x$ session interaction $[F(4,62)=2.68, p<0.05]$, session effect $[F(2,62)=12.84, p<0.001$, group effect $\mathrm{F}(2,31)=15.58, \mathrm{p}<0.001]$. Importantly, it showed that the number of rewards obtained was much lower in the nicotine+vanilla trained group compared to the vanilla alone group (post-hoc $\mathrm{p}<0.001$ ), indicating the detection of nicotine omission by the mice. There was a floor effect for nicotine only.

All groups were further tested with water only, and in the presence or in the absence of the visual cue light associated with the reward delivery (fig 5b). Repeated measure ANOVA showed no significant group effect, $[\mathrm{F}(2,31)=1.87, \mathrm{p}>0.05]$, but a significant visual cue effect $[\mathrm{F}(1,31)=7.47$, $\mathrm{p}<0.05]$ and a significant groupxvisual cue interaction $[\mathrm{F}(2,31)=5.81, \mathrm{p}<0.01]$.

\section{Motivation using progressive ratio for flavored nicotine decreases at highest concentrations}

Figure 6 Here

Motivation for the solution was tested using a progressive ratio schedule of reinforcement, results are presented on Fig6 a-f.

First, vanilla, nicotine+vanilla and nicotine were compared when the dose of nicotine tested was 40 $\mu \mathrm{g} / \mathrm{ml}$. Nicotine alone tended to initiate less active responding, but the number of active nose poke 
visits [one-way ANOVA, $\mathrm{F}(2,31)=1.37$, p>0.05; fig 6a] and the number of inactive nose poke visits [one-way ANOVA, F $(2,31)=0.95$, p>0.05; fig S2c] were not significantly different in the three groups. However, nicotine OSA significantly deceased the breaking point value [one-way ANOVA, $\mathrm{F}(2,31)=4.37, \mathrm{p}=0.02$; Tukey nicotine vs. nicotine+vanilla $\mathrm{p}<0.05$, nicotine vs. vanilla $\mathrm{p}=0.06$; fig 6b] and the session duration [one-way $\operatorname{ANOVA,~} \mathrm{F}(2,31)=4.86, \mathrm{p}=0.01$; Tukey nicotine vs. nicotine+vanilla $\mathrm{p}<0.05$; fig $6 \mathrm{c}]$.

Second, the motivation of the nicotine+vanilla group has been tested when increasing the dose of nicotine $(40-120 \mu \mathrm{g} / \mathrm{ml})$ in comparison to the vanilla group. Two-way ANOVA analysis on active responses emitted during the PR ratio showed a significant dose $\mathrm{x}$ group interaction $[\mathrm{F}(2,42)=3.127$, $\mathrm{p}=0.05]$. Flavored nicotine OSA trained animals decreased active responding when nicotine dose was increased (Tukey post-hoc, 80 or 120 vs. 40 p=0.05), while the active visits for vanilla controls were not significantly different from each other (post-hoc n.s.) (fig 6d). The analysis of the breaking point showed the same tendency [dose $x$ group interaction, $F(2,42)=2.88, p=0.06$ ] (fig 6e). Finally, ANOVA on the total time length of PR sessions indicated a significant interaction [dose $\mathrm{x}$ group, $\mathrm{F}$ $(2,42)=7.21, \mathrm{p}=0.002]$. Flavored nicotine group showed shorter session duration when nicotine dose was increased $[\mathrm{F}(2,22)=10.52, \mathrm{p}<0.001]$. Duration of the sessions at nicotine $120 \mu \mathrm{g} / \mathrm{ml}$ is shorter than session duration at nicotine $40 \mu \mathrm{g} / \mathrm{ml}(\mathrm{p}<0.001)$ and shorter than $80 \mu \mathrm{g} / \mathrm{ml}(\mathrm{p}=0.05)$ (fig 6f). This variable did not change for the vanilla control group $[F(2,20)=1.28, p=0.30]$.

Reinstatement of operant responding by presentation of the reward and reward-associated cue-light After a 30 min-extinction period, liquid reward and associated-cue light were presented in order to induce reinstatement of drug-seeking behavior, and finally there was the "no drug" period (fig 7a-c represents the active responses for each training dose and each step of the session)

Figure 7 Here

During the extinction period, and whatever the dose of training (40-120 $\mu \mathrm{g} / \mathrm{ml}$ nicotine), all groups demonstrated a similar decreased number of visits in the active hole (time main effect; nicotine 40: $[\mathrm{F}(5,155)=4.59, \mathrm{p}=0.002 ;$ nicotine $80: \mathrm{F}(5,105)=5.09, \mathrm{p}=0.002$; nicotine $120: \mathrm{F}(5,105)=14.87$, $\mathrm{p}<0.001]$

Presentation of the cue light and the liquid reward induced reinstatement of active seeking behavior in all mice, whatever the dose of nicotine received during OSA training. ANOVA including the average level of extinction on the 3 last time point and the 30-60 min period of the session indicated a time main effect for: $40 \mu \mathrm{g} / \mathrm{ml}[\mathrm{F}(6,186)=7.79$, $\mathrm{p}<0.001]$ (fig $7 \mathrm{a}), 80 \mu \mathrm{g} / \mathrm{ml}[\mathrm{F}(6,126)=4.10$, $\mathrm{p}=0.004]$ (fig $7 \mathrm{~b}$ ) and $120 \mu \mathrm{g} / \mathrm{ml}[\mathrm{F}(6,126)=5.53, \mathrm{p}=0.001]$ (fig 7c). However, vanilla, vanilla 
flavored nicotine or nicotine groups were not significantly different $[40 \mu \mathrm{g} / \mathrm{ml} \mathrm{F}(2,31)=0.74$, $\mathrm{p}=0.49,80 \mu \mathrm{g} / \mathrm{ml}[\mathrm{F}(1,21)=2.24, \mathrm{p}=0.15$ and $120 \mu \mathrm{g} / \mathrm{ml} \mathrm{F}(1,21)=0.26, \mathrm{p}=0.62]$. For all reinstatement tests, the time $x$ group interaction was not significant $(p=0.20, p=0.65$ and $p=0.74$ for 40,80 or $120 \mu \mathrm{g} / \mathrm{ml}$ respectively].

ANOVA on the no drug period indicated a significant decrease of active responding across time for both $40 \mu \mathrm{g} / \mathrm{ml}$ (ANOVA, $\mathrm{p}<0.001$ ) and $80 \mu \mathrm{g} / \mathrm{ml}$ (ANOVA, $\mathrm{p}<0.05$ ) training doses, but no significant difference between groups whatever the dose of training considered [40 $\mu \mathrm{g} / \mathrm{ml} \mathrm{F}(2,62)$ $=1.01, \mathrm{p}=0.37,80 \mu \mathrm{g} / \mathrm{ml} \mathrm{F}(1,42)=0.80, \mathrm{p}=0.38]$ and $120 \mu \mathrm{g} / \mathrm{ml} \mathrm{F}(1,42)=0.42, \mathrm{p}=0.52]$.

\section{Oral nicotine self-administration increases serum cotinine}

Figure 8 Here

Similar to the dose-response curve experiment, here nicotine intake is higher in mice trained with the dose $120 \mu \mathrm{g} / \mathrm{ml}$ than in mice trained with $40 \mu \mathrm{g} / \mathrm{ml}$ (T-test with Welch's correction, $\mathrm{t}=4.26$, $\mathrm{p}<0.01$, fig 8a). Subsequently, serum cotinine measures are also larger in mice receiving nicotine at $120 \mu \mathrm{g} / \mathrm{ml}$ compared to $40 \mu \mathrm{g} / \mathrm{ml}$ (T-test with Welch's correction, $\mathbf{t}=\mathbf{2 . 7 3}, \mathbf{p}=\mathbf{0 . 0 5}$, fig $8 \mathbf{b}$ ). Cotinine level was equal to zero in the serum of all mice trained for vanilla (data not shown).

\section{DISCUSSION}

Smoking reinforcement depends on both nicotine and non-nicotine components; however, the crucial role of non-nicotine factors in the facilitation of cigarette addiction remains to be understood (Rose 2006). The objective of this study was to investigate the effects of flavor additives on nicotine oral taking and seeking behaviors. Our hypothesis was twofold: first adding flavors to a nicotine solution would promote its volitional consumption, and second, would enhance the reinforcing value of nicotine to further invigorate taking and seeking behaviors.

As expected, the addition of nicotine to water reduced total liquid consumption corroborating an innate aversive reaction to the taste of the nicotine solution (Gyekis et al. 2012). Moreover, we found that the mix of flavoring additives to nicotine solution enhanced its consumption in a free-choice procedure. More specifically, our results indicated that vanilla 1\% was the optimal flavor condition that favored nicotine consumption and made the mixture isopalatable to vanilla $1 \%$ flavor in tap water. Vanillin (4-hydroxy-3-methoxybenzaldehyde) is the main component of natural vanilla, is 
generally rated as pleasant in both in humans and animals (Ogawa et al. 2018; Xu et al. 2015). Altogether, these findings suggest that the addition of vanilla to smoked (tobacco) and non-smoked (e-cig) nicotine products may increase the probability one repeats its exposure to nicotine since the flavor attractiveness surpasses nicotine harshness (Cooper et al. 2020; Patten and De Biasi 2020). Subsequently, it might facilitate the transition to nicotine addiction in vulnerable subjects (Morean et al. 2018; Patten and De Biasi 2020).

Nicotine oral consumption can change brain activity via the stimulation of specialized bitter taste receptors, which can be unpleasant and aversive. It stimulates the chorda tympani neurons which innervate taste buds classically responding to bitter tastes such as quinine (Dahl et al. 1997). Available studies on oral nicotine showed that drinking nicotine was neither palatable nor satisfactory for rodents; it also produced weight loss and large decreases in fluid intake (Enoch et al. 2001). In our study as well, animals having no other choice than nicotine diluted in water decreased their consumption compared to the basal water consumption. Animals do not like and more importantly, do not prefer nicotine. These results confirm the need to edulcorate nicotine solution with sucrose or saccharin to reduce the aversion for this solution (Nesil et al. 2011; Smith and Roberts 1995). Further, our data clearly suggest that flavor additives are sufficient to drive and maintain consumption of a nicotine-free solution. At the clinical level, while e-cig has been proposed for tobacco abstinence control, increasing body of evidence indicates that the numerous available flavor additives present in e-liquids enhance vape products palatability and attractiveness for new and non-smokers (Soule et al. 2016).

Having optimized the nicotine solution palatability with flavor additives, the aim was then to examine the development of nicotine taking and seeking behaviors in the model of oral selfadministration in mice. We compared the acquisition, maintenance and motivation for nicotine-alone compared to flavored nicotine solution, as well as the interaction between nicotine and the sensory cue in drug taking and drug seeking behaviors. Results indicated that while nicotine-alone poorly motivated oral self-administration, vanilla flavor was efficient to enhance the acquisition of nicotine oral self-administration. Moreover, we showed that changes in nicotine concentration or nicotine omission altered self-administration behavior. We sought to demonstrate that adding a flavor to the nicotine solution may enhance its rewarding value, thus mice motivation was tested in a progressive ratio and reinstatement tests. Our findings showed that motivation for the flavored nicotine solution was higher than the motivation for nicotine-alone, but still motivation was decreased when flavored nicotine dose was increased. Importantly, mice reinstated seeking behavior after the presentation of both oral and visual stimuli, underlying the role of environmental and drug-paired cues in nicotine 
self-administration. Analysis of cotinine blood contents confirmed that nicotine had been absorbed and had induced intoxication to nicotine relevant to the study of nicotine addiction. However, our results demonstrated that vanilla flavored nicotine did not induce more reward taking and seeking than the vanilla-alone solution.

Nicotine has strong reinforcement-enhancing properties in humans, using rewards such as videos and music (Perkins et al. 2017). Addressing this nicotine property may have important clinical implications such as the understanding of the persistence of tobacco dependence despite the use of successful pharmacotherapies. The preclinical research has largely tackled the problem and has reached similar conclusions. Nicotine administration, whether given contingently or not, enhances responding to contextual cues and non-drug rewards such as lights or sweet taste associated with its self-administration and can thus allow cues to influence its subsequent taking (Chaudhri et al. 2006; Chaudhri et al. 2007; Grimm et al. 2012; Palmatier et al. 2012). More specifically, nicotine also increases the reinforcing effects of sucrose and sucrose-paired cues (Barret and Bevins 2013) as well as the incentive value and the motivation of animals for these liquid rewards (Grimm et al. 2012). Nevertheless, in our experimental conditions we could not evidence nicotine-induced reinforcement onto the vanilla flavor. We expected vanilla to increase nicotine rewarding value and to further invigorate nicotine oral self-administration. However, vanilla taking mice performed as well as vanilla flavored nicotine taking mice, suggesting that the bidirectional interaction failed to happen. Finally, testing nicotine and flavor interaction under a progressive-ratio (PR) schedule minimized the odds of reward satiation as an explanation for the failure to have increased motivation for flavored nicotine.

We should acknowledge several limitations for this study. First, only male mice were tested and we will further investigate the question of combined nicotine with aromatic additive in female mice in a model refining the exposure to nicotine. Second, the oral route of nicotine administration may have altered the efficiency of the operant learning. Most studies so far had used systemic or intravenous route of administration which favors the rapidity of action of nicotine, the detection of its interoceptive signal and its central effects (Lenoir and Kiyatkin 2011). Then, the stimulusreinforcer association learning typically occurs and contribute to the attribution of incentive motivation to the drug-associated cues. In our conditions, the rate of entry of nicotine into the brain must have been too slow, which did not allow reaching optimal condition for reinforcement.

Nonetheless, the sustained motivation for vanilla flavor solution taking and seeking in mice further underlines its sensory appealing properties and demonstrates that it might be a key factor increasing tobacco and vaping attractiveness. Actually, the attractiveness of e-liquid flavors to non-smoking 
youth have been shown to promote the use of electronic devices and consumption of nicotine (Harrell et al. 2017; Harrell et al. 2017). Vanilla is the most widely used flavor (Krusemann et al. 2019). Vanillin is perceived as similar to sucrose at low concentrations and has also been proven to have a reinforcing effect on appetite (Ogawa et al. 2018). The use of vanilla flavor as a tobacco additive has been regulated for conventional cigarettes; however, no regulations exist so far for its use in eliquids and smokeless tobacco products. Unclear is whether e-liquids with all available attractive flavors including vanillin will serve as smoking cessation aid or if it will promote the appeal for ENDS vaping and induce a new form of nicotine addiction. Additional preclinical research is required to explore this new hypothesis.

In conclusion, our data highlight the complexity of modeling transition to nicotine addiction in mice self-administering nicotine in solution, with the ambiguity to decipher the interactions between multisensory stimuli as well as nicotine's increasing aversiveness at high concentrations. We show that by 1) modifying oral sensory perception and 2) positively influencing the affective valence associated with nicotine, aromatic additives contained in e-liquids could therefore play a major role in the initiation of e-cig consumption. Recent clinical studies and our investigation further emphasize the appeal of flavors and their reinforcing effects. Thus, future experiment designs should be refined in order to fill the gaps left, regarding the key role of the smoking/ vaping oral signals in the transition to nicotine addiction.

\section{REFERENCES}

Ayo-Yusuf OAAgaku IT (2015) The association between smokers' perceived importance of the appearance of cigarettes/cigarette packs and smoking sensory experience: a structural equation model. Nicotine Tob Res 17(1):91-97.

Barret STBevins RA (2013) Nicotine enhances operant responding for qualitatively distinct reinforcers under maintenance and extinction conditions. Pharmacol Biochem Behav 114-115:9-15.

Biswas L, Harrison E, Gong Y, Avusula R, Lee J, Zhang M, Rousselle T, Lage J, Liu X (2016) Enhancing effect of menthol on nicotine self-administration in rats. Psychopharmacology (Berl) 233(18):3417-3427.

Chaudhri N, Caggiula AR, Donny EC, Booth S, Gharib M, Craven L, Palmatier MI, Liu X, Sved AF (2006) Operant responding for conditioned and unconditioned reinforcers in rats is differentially enhanced by the primary reinforcing and reinforcement-enhancing effects of nicotine. Psychopharmacology (Berl) 189(1):27-36.

Chaudhri N, Caggiula AR, Donny EC, Booth S, Gharib M, Craven L, Palmatier MI, Liu X, Sved AF (2007) Selfadministered and noncontingent nicotine enhance reinforced operant responding in rats: impact of nicotine dose and reinforcement schedule. Psychopharmacology (Berl) 190(3):353-362. 
Chaudhri N, Caggiula AR, Donny EC, Palmatier MI, Liu X, Sved AF (2006) Complex interactions between nicotine and nonpharmacological stimuli reveal multiple roles for nicotine in reinforcement. Psychopharmacology (Berl) 184(3-4):353-366.

Clemens KJ, Caille S, Cador M (2010) The effects of response operandum and prior food training on intravenous nicotine self-administration in rats. Psychopharmacology (Berl) 211(1):43-54.

Cohen A, Koob GF, George O (2012) Robust escalation of nicotine intake with extended access to nicotine selfadministration and intermittent periods of abstinence. Neuropsychopharmacology 37(9):2153-2160.

Collins AC, Pogun S, Nesil T, Kanit L (2012) Oral Nicotine Self-Administration in Rodents. J Addict Res Ther S2.

Cooper SY, Akers AT, Henderson BJ (2020) Flavors enhance nicotine vapor self-administration in male mice. Nicotine Tob Res.

Dahl M, Erickson RP, Simon SA (1997) Neural responses to bitter compounds in rats. Brain Res 756(1-2):22-34.

Enoch MA, Harris CR, Goldman D (2001) Does a reduced sensitivity to bitter taste increase the risk of becoming nicotine addicted? Addict Behav 26(3):399-404.

Grieder TE, Herman MA, Contet C, Tan LA, Vargas-Perez H, Cohen A, Chwalek M, Maal-Bared G, Freiling J, Schlosburg JE, Clarke L, Crawford E, Koebel P, Repunte-Canonigo V, Sanna PP, Tapper AR, Roberto M, Kieffer BL, Sawchenko PE, Koob GF, van der Kooy D, George O (2014) VTA CRF neurons mediate the aversive effects of nicotine withdrawal and promote intake escalation. Nat Neurosci 17(12):1751-1758.

Grimm JW, Ratliff C, North K, Barnes J, Collins S (2012) Nicotine increases sucrose self-administration and seeking in rats. Addict Biol 17(3):623-633.

Gyekis JP, Dingman MA, Revitsky AR, Bryant BP, Vandenbergh DJ, Frank ME, Blizard DA (2012) Gustatory, trigeminal, and olfactory aspects of nicotine intake in three mouse strains. Behav Genet 42(5):820-829.

Harrell MB, Loukas A, Jackson CD, Marti CN, Perry CL (2017) Flavored Tobacco Product Use among Youth and Young Adults: What if Flavors Didn't Exist? Tob Regul Sci 3(2):168-173.

Harrell MB, Weaver SR, Loukas A, Creamer M, Marti CN, Jackson CD, Heath JW, Nayak P, Perry CL, Pechacek TF, Eriksen MP (2017) Flavored e-cigarette use: Characterizing youth, young adult, and adult users. Prev Med Rep 5:33-40.

Harris AC, Muelken P, Swain Y, Palumbo M, Jain V, Goniewicz ML, Stepanov I, LeSage MG (2019) Non-nicotine constituents in e-cigarette aerosol extract attenuate nicotine's aversive effects in adolescent rats. Drug Alcohol Depend 203:51-60.

Krusemann EJZ, Boesveldt S, de Graaf K, Talhout R (2019) An E-Liquid Flavor Wheel: A Shared Vocabulary Based on Systematically Reviewing E-Liquid Flavor Classifications in Literature. Nicotine Tob Res 21(10):13101319.

Krusemann EJZ, Lasschuijt MP, de Graaf C, de Wijk RA, Punter PH, van Tiel L, Cremers J, van de Nobelen S, Boesveldt S, Talhout R (2019) Sensory analysis of characterising flavours: evaluating tobacco product odours using an expert panel. Tob Control 28(2):152-160.

Lee LY, Gerhardstein DC, Wang AL, Burki NK (1993) Nicotine is responsible for airway irritation evoked by cigarette smoke inhalation in men. J Appl Physiol (1985) 75(5):1955-1961.

Lenoir MKiyatkin EA (2011) Critical role of peripheral actions of intravenous nicotine in mediating its central effects. Neuropsychopharmacology 36(10):2125-2138.

Morean ME, Butler ER, Bold KW, Kong G, Camenga DR, Cavallo DA, Simon P, O'Malley SS, Krishnan-Sarin S (2018) Preferring more e-cigarette flavors is associated with e-cigarette use frequency among adolescents but not adults. PLoS One 13(1):e0189015.

Nesil T, Kanit L, Collins AC, Pogun S (2011) Individual differences in oral nicotine intake in rats. Neuropharmacology 61(1-2):189-201.

Nesil T, Narmeen S, Bakhti-Suroosh A, Lynch WJ (2019) Effect of menthol on nicotine intake and relapse vulnerability in a rat model of concurrent intravenous menthol/nicotine self-administration. Psychopharmacology (Berl) 236(4):1219-1232.

Ogawa K, Tashima A, Sadakata M, Morinaga O (2018) Appetite-enhancing effects of vanilla flavours such as vanillin. J Nat Med 72(3):798-802.

Palmatier MI, Lantz JE, O'Brien LC, Metz SP (2013) Effects of nicotine on olfactogustatory incentives: preference, palatability, and operant choice tests. Nicotine Tob Res 15(9):1545-1554.

Palmatier MI, O'Brien LC, Hall MJ (2012) The role of conditioning history and reinforcer strength in the reinforcement enhancing effects of nicotine in rats. Psychopharmacology (Berl) 219(4):1119-1131. 
Palmatier MI, Smith AL, Odineal EM, Williams EA, Sheppard AB, Bradley CA (2020) Nicotine Self-Administration With Tobacco Flavor Additives in Male Rats. Nicotine Tob Res 22(2):224-231.

Patten TDe Biasi M (2020) History repeats itself: Role of characterizing flavors on nicotine use and abuse. Neuropharmacology 177:108162.

Perkins KA, Karelitz JL, Boldry MC (2017) Nicotine Acutely Enhances Reinforcement from Non-Drug Rewards in Humans. Front Psychiatry 8:65.

Rose JE (2006) Nicotine and nonnicotine factors in cigarette addiction. Psychopharmacology (Berl) 184(3-4):274285.

Shalev U, Grimm JW, Shaham Y (2002) Neurobiology of relapse to heroin and cocaine seeking: a review. Pharmacol Rev 54(1):1-42.

Smith ARoberts DC (1995) Oral self-administration of sweetened nicotine solutions by rats. Psychopharmacology (Berl) 120(3):341-346.

Soule EK, Lopez AA, Guy MC, Cobb CO (2016) Reasons for using flavored liquids among electronic cigarette users: A concept mapping study. Drug Alcohol Depend 166:168-176.

Vandaele Y, Noe E, Cador M, Dellu-Hagedorn F, Caille S (2018) Attentional capacities prior to drug exposure predict motivation to self-administer nicotine. Psychopharmacology (Berl) 235(7):2041-2050.

Vogel EA, Prochaska JJ, Ramo DE, Andres J, Rubinstein ML (2019) Adolescents' E-Cigarette Use: Increases in Frequency, Dependence, and Nicotine Exposure Over 12 Months. J Adolesc Health 64(6):770-775.

Wickham RJ, Nunes EJ, Hughley S, Silva P, Walton SN, Park J, Addy NA (2018) Evaluating oral flavorant effects on nicotine self-administration behavior and phasic dopamine signaling. Neuropharmacology 128:33-42.

Xu J, Xu H, Liu Y, He H, Li G (2015) Vanillin-induced amelioration of depression-like behaviors in rats by modulating monoamine neurotransmitters in the brain. Psychiatry Res 225(3):509-514.

Zhang M, Harrison E, Biswas L, Tran T, Liu X (2018) Menthol facilitates dopamine-releasing effect of nicotine in rat nucleus accumbens. Pharmacol Biochem Behav 175:47-52.

Zhu SH, Sun JY, Bonnevie E, Cummins SE, Gamst A, Yin L, Lee M (2014) Four hundred and sixty brands of ecigarettes and counting: implications for product regulation. Tob Control 23 Suppl 3:iii3-9.

\section{FIGURE LEGENDS}


Fig.1 Timeline of the experiments. First, drinking behavior was characterized in a free access condition in mice aged PND35 at the start of the experiment (a). Mice basal consumption of water and nicotine $(\mathrm{n}=14,60 \mu \mathrm{g} / \mathrm{ml})$ were measured using one-bottle access; and next, mice had access to vanilla $(n=7)$ or coconut $(n=7)$ flavored solutions using a two-bottle choice design. Liquid intake was evaluated at the end of each specific test from day 1 (D1) to day 22 (D22). In the second experiment (b), mice aged PND35-40 at the start of the experiment were pre-trained for operant responding with liquid saccharin (Sacch) $0.1 \%$ on fixed ratio 1 and 2 (FR1 \& FR2) schedules of reinforcement. Then, mice were tested for oral flavored nicotine $(40 \mu \mathrm{g} / \mathrm{ml})$ self-administration using vanilla flavor $1 \%$ (vanilla flavored nicotine, $n=12$; and control vanilla, $n=11$ ). Mice were tested for acquisition, motivation, sensitivity and reinstatement at nicotine doses ranging from 40 to $120 \mu \mathrm{g} / \mathrm{ml}$. At the end of the experiment, myocardial blood sampling was performed for serum cotinine dosage

Fig.2 Effects of flavor additives on nicotine aversive taste. (a) Basal liquid intake for water or nicotine $(60 \mu \mathrm{g} / \mathrm{ml})$ when presented in one-bottle condition $(\mathrm{n}=14),(\mathrm{b})$ in a two-bottle choice design, dose-response preference score for coconut (dotted white) or vanilla (grey) $(0.01,0.1$ and 1\%) flavored nicotine over water ( $\mathrm{n}=7 /$ flavor), (c) Preference score for vanilla flavored nicotine over vanilla flavored water (flavor concentration 0.1 and $1 \%, \mathrm{n}=7$ ). ${ }^{*} \mathrm{p}<0.05, * * * \mathrm{p}<0.001$ paired t-test; $\# \mathrm{p}<0.05$, \#\# $\mathrm{p}=0.01$ comparison to standard value of $50 \%$ preference. All data are represented as mean \pm SEM

Fig.3 Acquisition of oral self-administration of vanilla 1\% flavored nicotine. Vanilla 1\% $(n=11)$, nicotine $(\mathrm{n}=11)$ and flavored nicotine $40 \mu \mathrm{g} / \mathrm{ml}(\mathrm{n}=12)$; (a) Number active nose-pokes and b) Number of rewards (average over the last 3 sessions) for each schedule of reinforcement: FR2 \& FR3 30 min-session and FR3 60min-session; Repeated measure ANOVA on rewards shows a significant group effect. All data are expressed as mean \pm SEM

Fig.4 Dose-response characteristics during oral self-administration of nicotine $(n=11)$ and vanilla $1 \%$ flavored nicotine $(\mathrm{n}=12)$. Rising doses of nicotine from 0 to $80 \mu \mathrm{g} / \mathrm{ml}$ resulted in decreased (a) Number of visits in the active nose poke hole as well as (b) Number of rewards; while nicotine intake increased in both groups. Repeated measure ANOVA indicated that nicotine-alone group was always lower than nicotine+vanilla. * $\mathrm{p}<0.05$ Sidak comparison nicotine vs. nicotine+vanilla; $\# \mathrm{p}<0.001$ main group effect. All data are represented as mean \pm SEM

Fig.5 Effects of nicotine and nicotine-associated cue omission tests on oral self-administration in vanilla $1 \%(n=11)$, nicotine $(n=11)$ and vanilla $1 \%$ flavored nicotine $(n=12)$ groups. Nicotine omission test on (a) the number of rewards during 3 consecutive FR3 30min sessions; Tukey posthoc@@ $<0.001$ nicotine+vanilla vs. vanilla. Nicotine-associated cue omission test on (b) the number of rewards during FR3 30min sessions in the presence or absence of the cue-light contingent with reward delivery. ANOVA, $\# \# \mathrm{p}<0.01$, cue-light main effect. The dotted line on each graphic represents the average value of rewards obtained in normal FR3 conditions for flavored nicotine group. All data are represented as mean \pm SEM

Fig.6 Progressive Ratio responding for vanilla 1\% flavored-nicotine oral self-administration. (a/d) number of active nose-pokes (b/e) breaking point values and (c/f) duration for each PR2. First, vanilla $1 \%$ (grey bars, $n=11$ ), nicotine (white bars, $n=11$ ), vanilla $1 \%$ flavored nicotine (black bars, $\mathrm{n}=12$ ) groups were compared for nicotine $40 \mu \mathrm{g} / \mathrm{ml}$ on the variables describing motivation: nicotine- 
alone mice showed reduction in breaking point and session duration, Tukey post-hoc nicotine vs. nicotine+vanilla $* \mathrm{p}<0.05$. Nicotine doses ranging from 40 to $120 \mu \mathrm{g} / \mathrm{ml}$ were also tested. Tukey multiple comparisons on nicotine doses, $\# \mathrm{p}<0.05, \# \# \mathrm{p}<0.01$. All data are represented as mean $\pm \mathrm{SEM}$

Fig.7 Cue light and nicotine-induced reinstatement in nicotine $(\mathrm{n}=11)$, vanilla $1 \%$ flavored nicotine $(\mathrm{n}=12)$ and vanilla $1 \%(\mathrm{n}=11)$ groups. Tests were performed for each training dose: (a) $40 \mu \mathrm{g} / \mathrm{ml}$, (b) $80 \mu \mathrm{g} / \mathrm{ml}$ and (c) $120 \mu \mathrm{g} / \mathrm{ml}$. Number of visits in the active nose-poke hole were recorded dured each step of the test session: "extinction", "reinstatement" and "no drug signal". Repeated measures ANOVA on extinction, reinstatement and "no drug signal" showed significant time effects, * $\mathrm{p}<0.05$, $* * \mathrm{p}<0.01, * * * \mathrm{p}<0.001$. All data are represented as mean \pm SEM

Fig.8 Serum cotinine measures at 90 min-post-OSA session with vanilla $1 \%$ nicotine $40 \mu \mathrm{g} / \mathrm{ml}(\mathrm{n}=7)$ and $120 \mu \mathrm{g} / \mathrm{ml}(\mathrm{n}=5)$. (a) Total nicotine intake $(\mu \mathrm{g})$ during the last OSA session and (b) serum cotinine levels $(\mathrm{ng} / \mathrm{mL})$ at $90 \mathrm{~min}$ post-session. T-test comparison followed by Welch's correction, $* \mathrm{p}<0.05, * * \mathrm{p}<0.01$. Data represented as median with range

Fig.S1 Saccharin pretraining: oral self-administration of saccharin $0.1 \%$ solution. Performances are given with respect to the mice distribution during nicotine oral self-administration: vanilla $1 \%$ (grey bars and dots, $n=11$ ), nicotine+vanilla $1 \%$ (black bars and dots, $n=12$ ) and nicotine (white bars and odts, $n=12$ ); (a) Number active and inactive nose-pokes (average over the last 3 sessions) and b) Number of rewards on the last day of training on FR2 schedule of reinforcement. ${ }^{*} p<0.05$ main effect operant responding. All data are expressed as mean \pm SEM

Fig.S2 Number of inactive nose poke visits at different steps of nicotine oral self-administration for vanilla $1 \%$ (grey bars and dots, $n=11$ ), nicotine+vanilla $1 \%$ (black bars and dots, $n=12$ ) and nicotine (white bars and dots, $n=12$ ) groups. Visits during a) acquisition of fixed ratio schedules, $b$ ) nicotine dose-response curve and c) progressive ratio test. ${ }^{*} \mathrm{p}<0.05$ Tukey multiple comparisons on groups. All data are expressed as mean \pm SEM 
FIGURE 1

1

FIGURE 2

a) Free access consumption

\begin{tabular}{|c|c|c|c|}
\hline \multicolumn{2}{|c|}{1 bottle consumption } & \multicolumn{2}{|c|}{ 2-bottle choice } \\
\hline $\begin{array}{l}\text { Water } \\
\text { (D1-D3) }\end{array}$ & $\begin{array}{c}\text { Nicotine } \\
60 \mu g / m l \\
\text { (D9) }\end{array}$ & $\begin{array}{l}\text { Flavored nicotine } \\
\text { vs. water } \\
\text { (D18-D20) }\end{array}$ & $\begin{array}{l}\text { Vanilla + nicotine } \\
\text { vs. vanilla } \\
\text { (D21-D22) }\end{array}$ \\
\hline \multicolumn{4}{|c|}{ Indicative Time (Days) } \\
\hline
\end{tabular}

b) Operant oral self-administration

\begin{tabular}{|c|c|c|c|c|c|c|c|}
\hline Sacch $0.1 \%$ & \multicolumn{7}{|c|}{ Nicotine in vanilla filavor $1 \%$} \\
\hline No nicotine & \multicolumn{4}{|c|}{$40 \mu \mathrm{g} / \mathrm{ml}$} & $80 \mu \mathrm{g} / \mathrm{ml}$ & $120 \mu \mathrm{g} / \mathrm{ml}$ & $40 \& 120 \mu \mathrm{g} / \mathrm{ml}$ \\
\hline $\begin{array}{l}\text { Pre-training } \\
\text { FR1-FR2 }\end{array}$ & $\begin{array}{l}\text { Acquisition } \\
\text { FR2-FR3 }\end{array}$ & $\begin{array}{l}\text { Motivation } \\
\text { PR2 }\end{array}$ & $\begin{array}{l}\text { Drug \& cue } \\
\text { sensitivity } \\
\text { FR3 }\end{array}$ & $\begin{array}{l}\text { Extinction \& } \\
\text { reinstatement }\end{array}$ & $\begin{array}{l}\text { Acquisition FR3 } \\
\text { Motivation PR2 } \\
\text { Reinstatement }\end{array}$ & $\begin{array}{l}\text { Acquisition FR3 } \\
\text { Motivation PR2 } \\
\text { Reinstatement }\end{array}$ & $\begin{array}{c}\text { Re-training } \\
\text { Blood samples }\end{array}$ \\
\hline \multicolumn{8}{|c|}{ Indicative Time (Weeks) } \\
\hline & & & & & & & \\
\hline
\end{tabular}

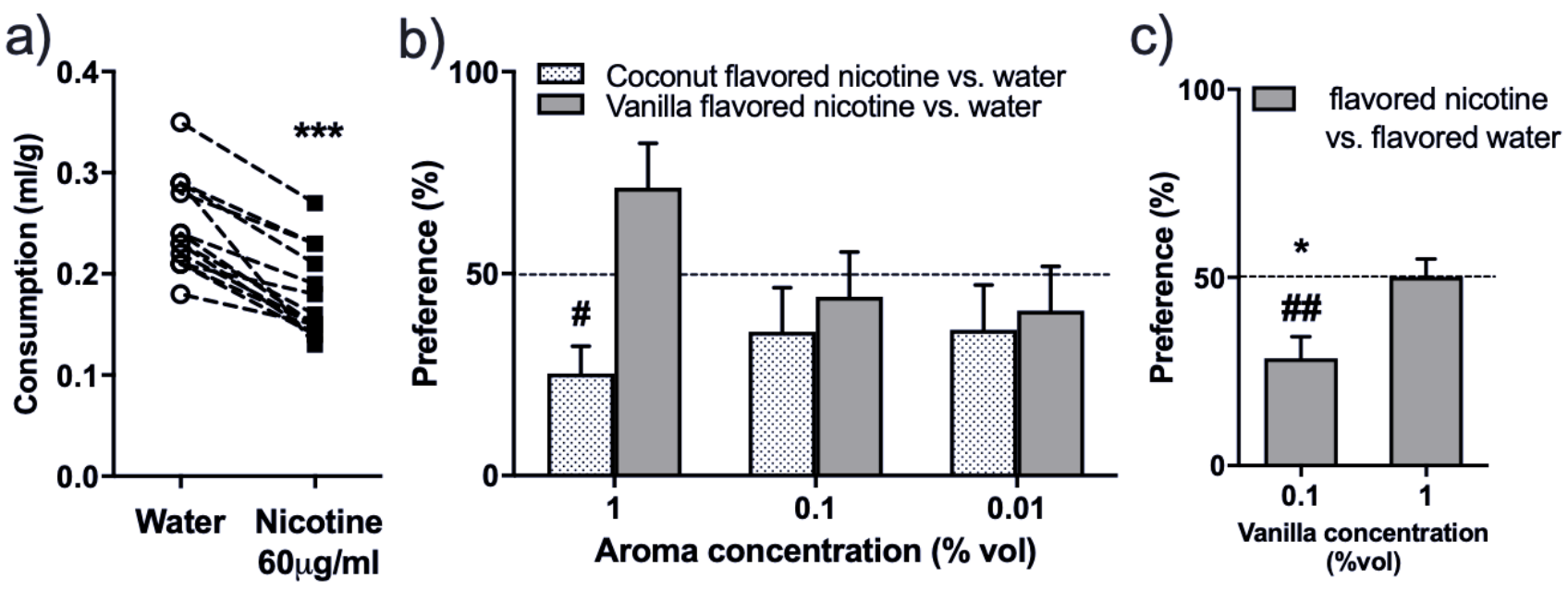


FIGURE 3

12

2

3

4

5

6

7

8

9

10

11

12

13

14

15

\section{FIGURE 4}

b)
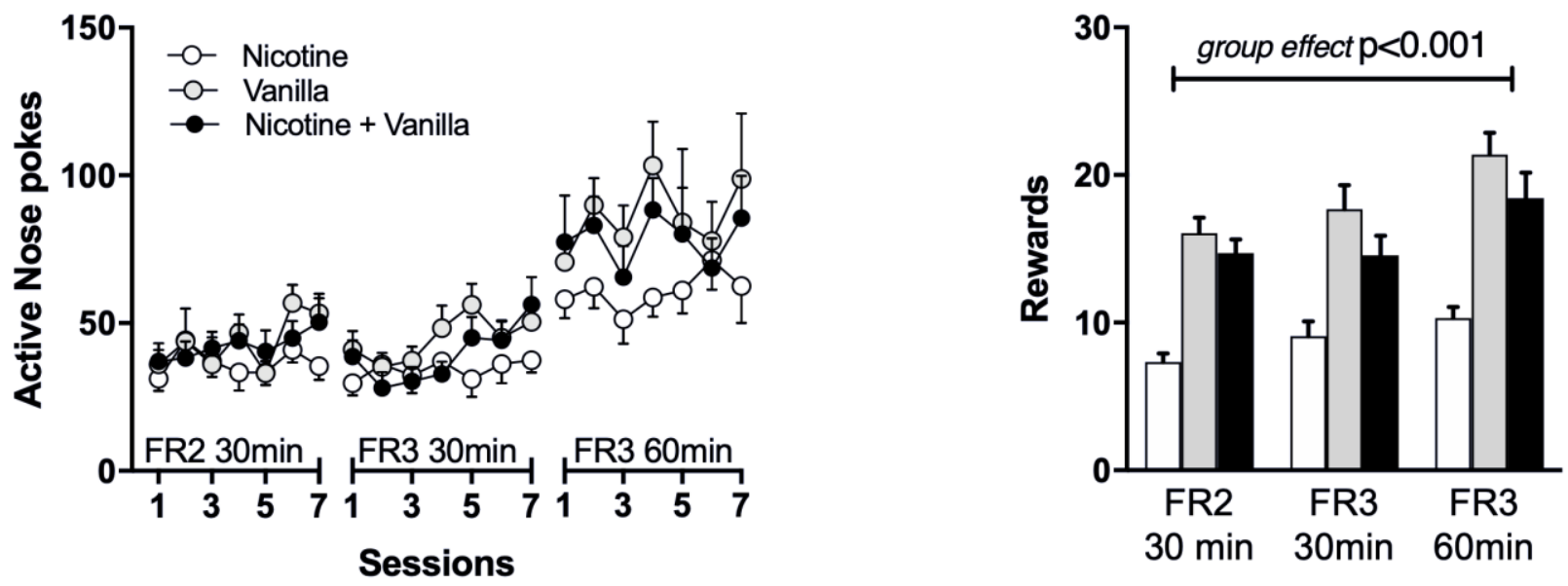

a)

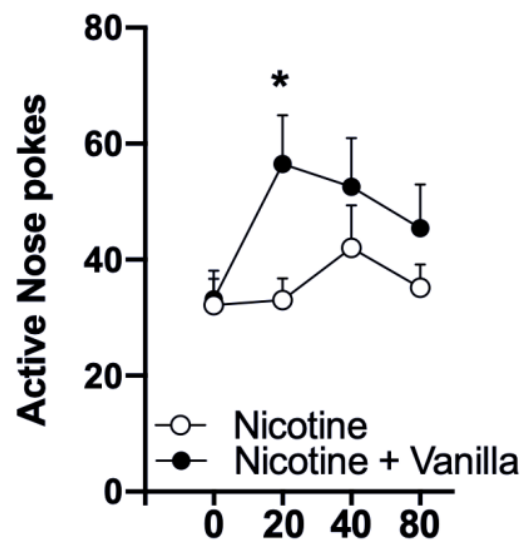

b)

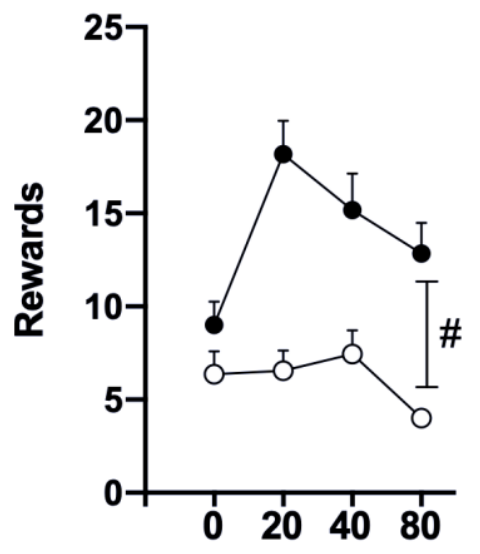

c)

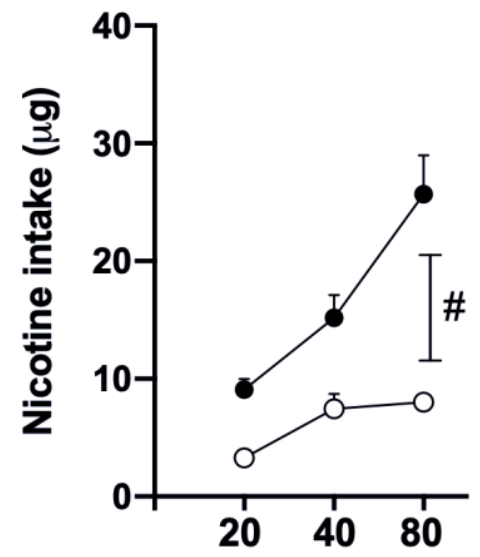

Nicotine $(\mu \mathrm{g} / \mathrm{ml})$ 
FIGURE 5

12

2

3

4

5

6

7

8

9

10

11

12

13

14

15

16

17 a)

Nicotine omission

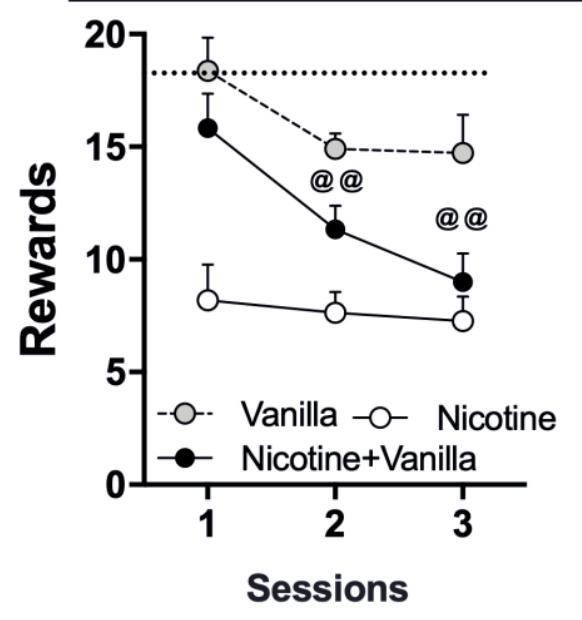

b) Nicotine-associated cues omission

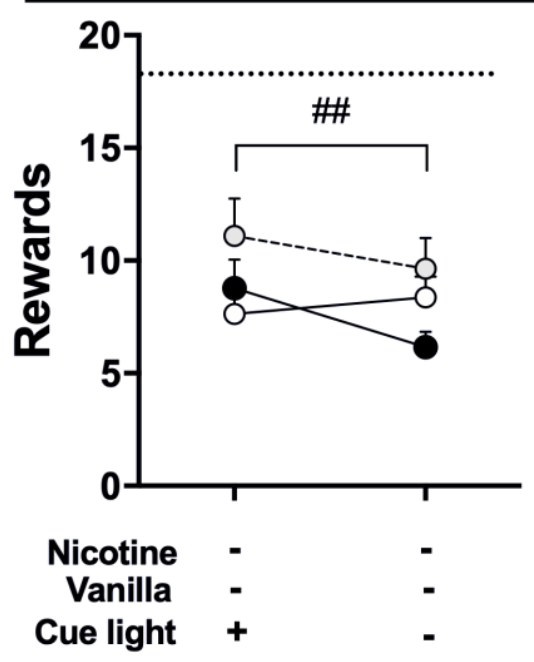

FIGURE 6

\section{Nicotine 40 $\mathrm{\mu g} / \mathrm{ml}$}

a)

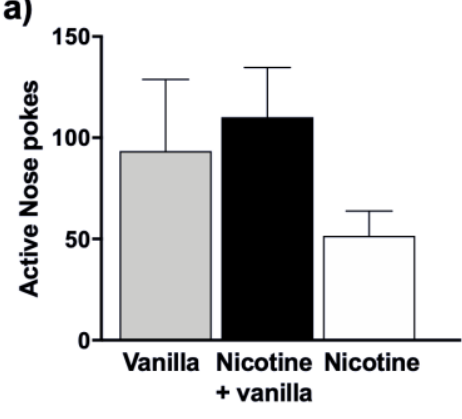

d)

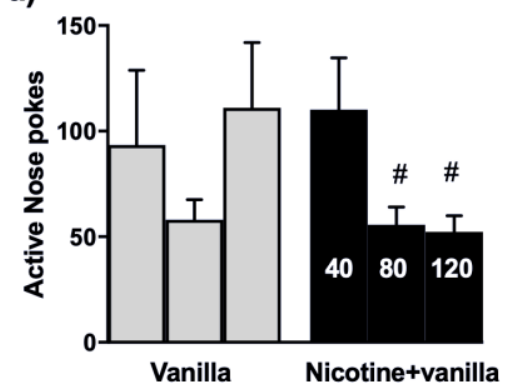

b)

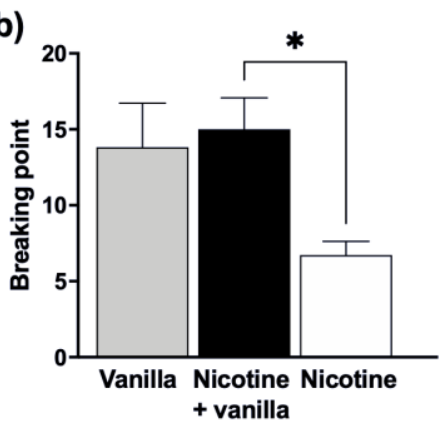

e)

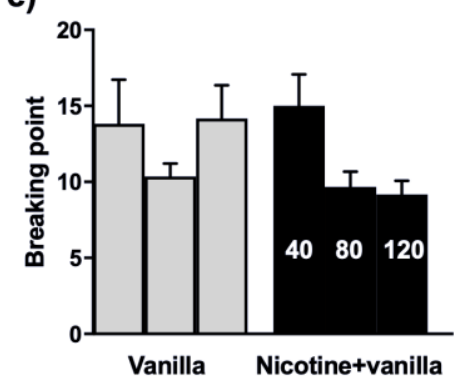

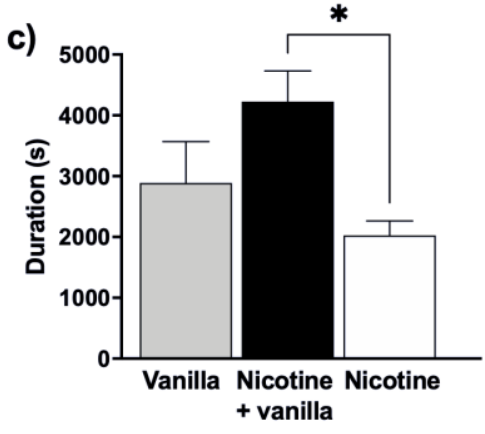

f)

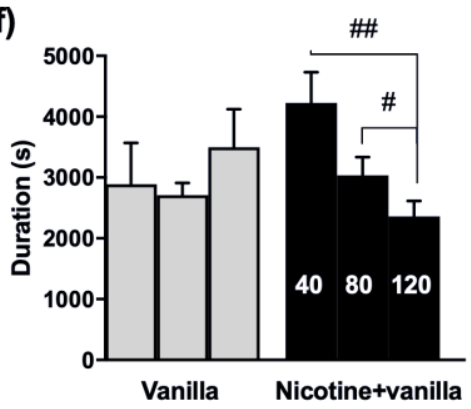


FIGURE 7

I

2

3

4

5

6

7

8
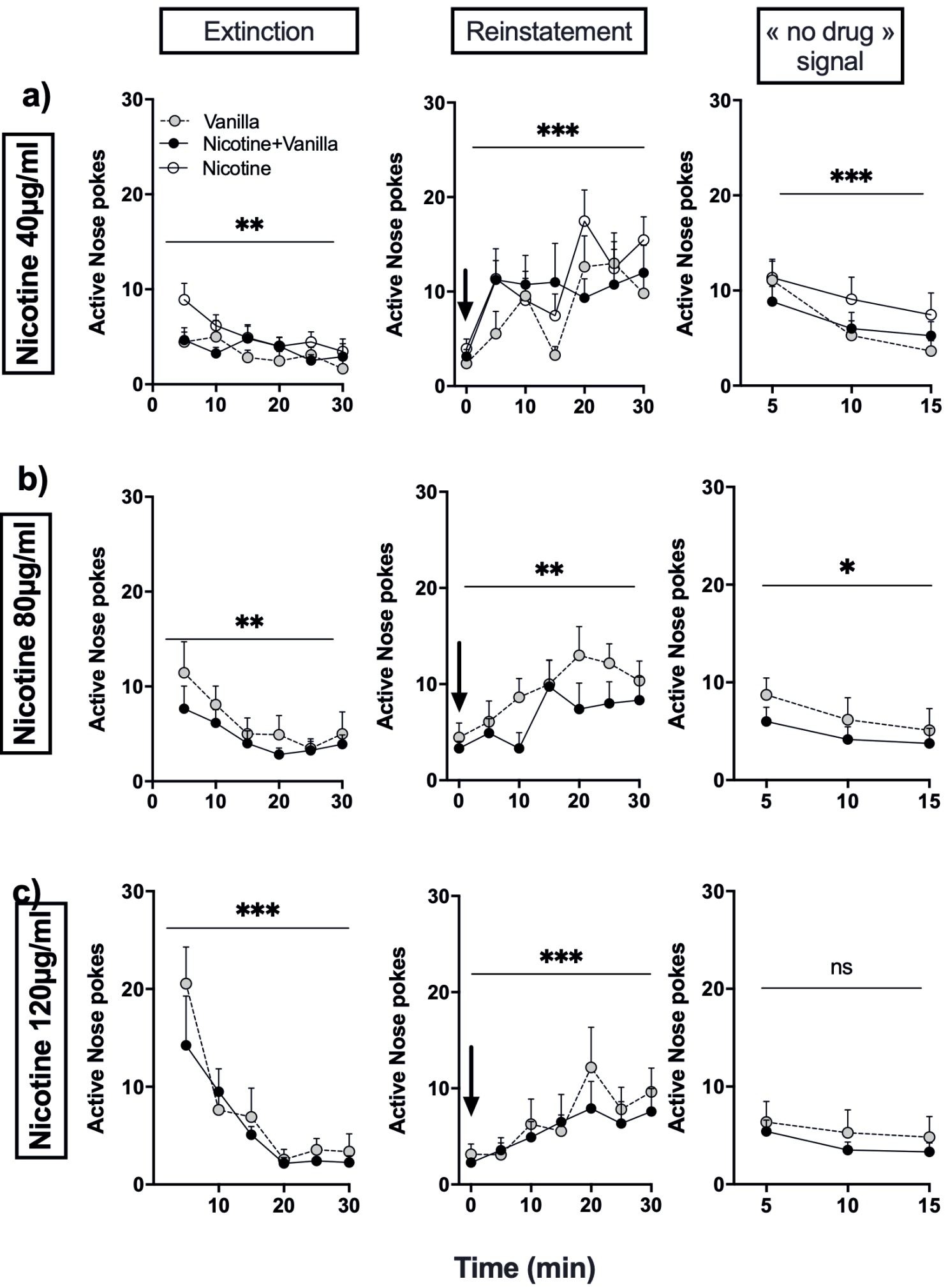
FIGURE 8

a)

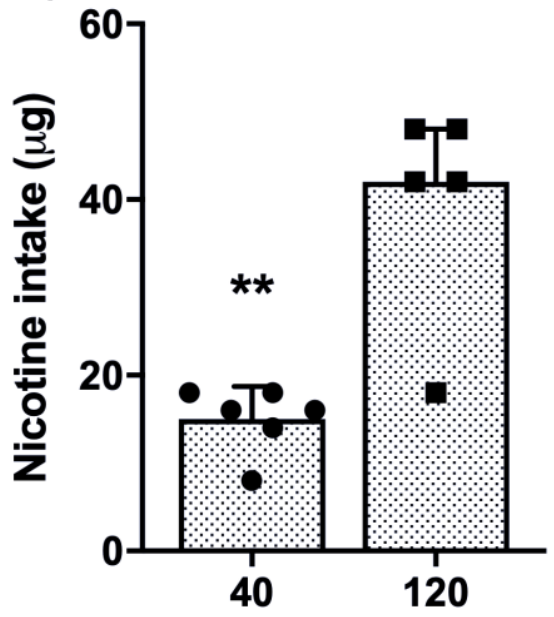

b)

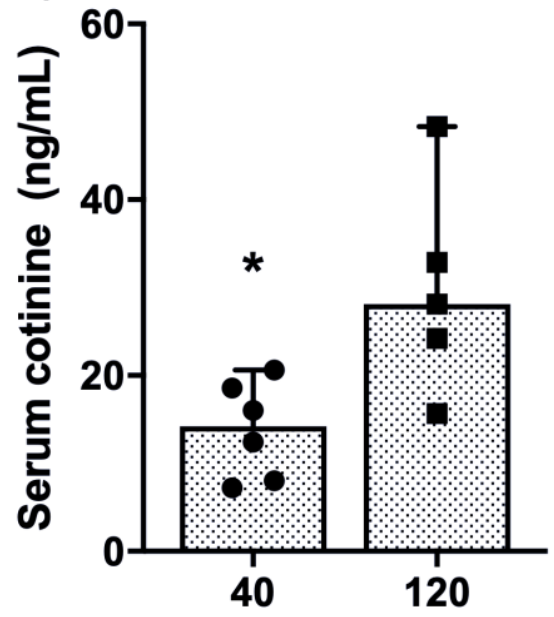

FIGURE SUPPLEMENTAL 1

a)

Vanilla $\square$ Nicotine - Nicotine + Vanilla

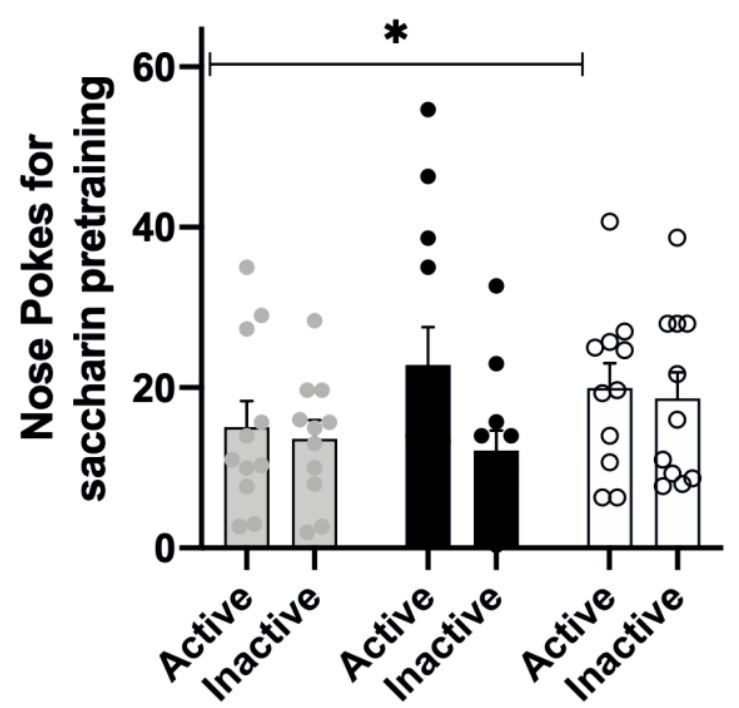

b)

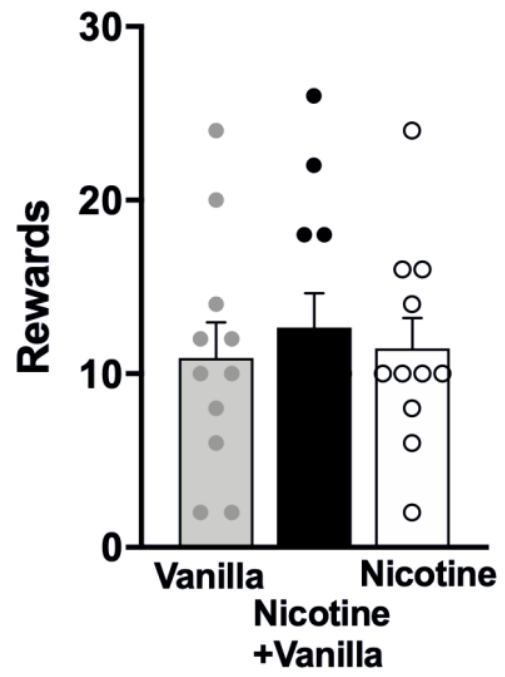

52
53 
FIGURE SUPPLEMENTAL 2

D

2

3

4

5

6

7

8

9

10

11

12

13

14

15

16

17

18

19

20

21

22

23

24

25

26

27

28

29

30

31

32

33

34

35

36

37

38

39

40

41

42

43

44

45

46

47

48

49

50

51

52

53

54

55

56

57

58

59

60

61

62

63

64

65 a) $\quad \square$ Vanilla $\square$ Nicotine

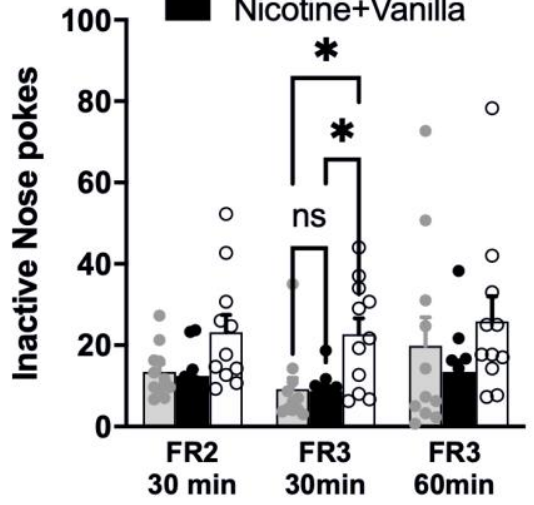

b)

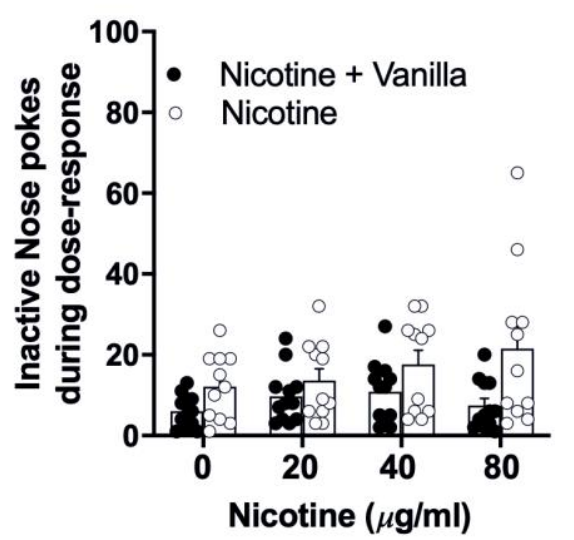

c)

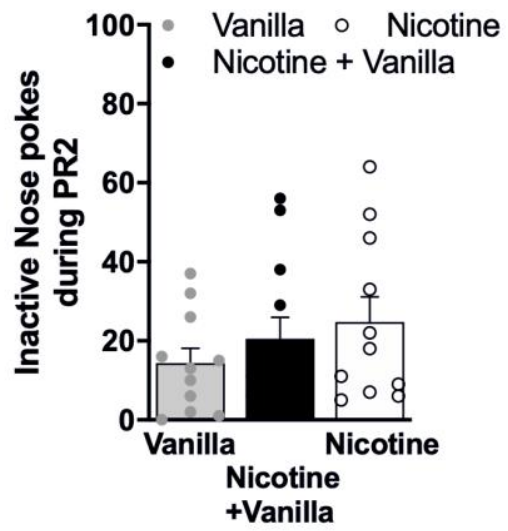

